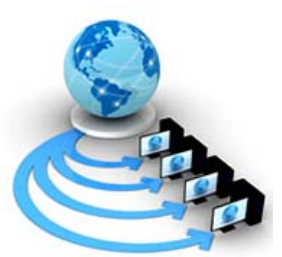

Volume 8, No. 9, November-December 2017

International Journal of Advanced Research in Computer Science

RESEARCH PAPER

Available Online at www.ijarcs.info

\title{
AN EASY, SMART \& INTELLIGENT WAY TO LEARN: “ONLINE EDUCATION”
}

\author{
Prince Sharma, Kaptan Bhardwaj, Divya Bhardwaj \\ BTech Scholar, ${ }^{2}$ BTech Scholar, ${ }^{3}$ Assistant Professor \\ Department of Computer Science \& Engineering \\ Panipat Institute of Engineering \& Technology \\ Samalkha, Panipat, Haryana,India
}

\begin{abstract}
Modern Technology has become an integral part of every aspect of our day-to-day life. Education system is also going through a big transformation these days with the introduction of multimedia tools in delivering the knowledge. Along with these tools, Online Education has become a big leap in the advancement of the Education system. The way a person is taught lays a huge impact on the person's mindset towards the world. With the Online Education the major factor affecting the quality of education has shifted from the ability of the teacher to the enthusiasm of the learner to learn new things.
\end{abstract}

Keywords: Online Education (OE), Oracle, Eclipse, Structured Query Language (SQL), Integrated Development Environment (IDE)

\section{INTRODUCTION}

Online Education (OE) is a modern approach that uses effective multimedia tools and interactive network to enhance the learning experience of the learner. $\mathrm{OE}$ is a learner centered [1] approach and focuses majorly on providing the freedom of "When, Where and What to learn" to the learner. Unlike the traditional method of learning where all the students are taught in a common way and at the same pace, With OE, the learner can access the content using the internet according to his need and learn things at his own pace. The learner does not necessarily need to attend the classes in person and has no problem of missing an important lecture.

Starting with an idea of using motion picture to use the Internet which is one of the most powerful resources of the modern world, the development of OE has been a very gradual process. In 1922, the famous inventor Thomas Edison said that "the motion picture is destined to revolutionize our educational system and that in a few years it will supplant the use of textbooks”. Almost a century later similar claims are made for the potential of multimedia learning environment.

Over the last few years many people have realized the potential held by the $\mathrm{OE}$ and have supported its implementation not only in the educational institutes but also in other domains. From corporate sector for the training of the employees' located miles away, using video conferencing, to the field of research where a scientist in India can share the results of his work for others to take it to the next level. With the implementation of OE, the distant education has taken a new shape as the students are finding $\mathrm{OE}$ more convenient and cost effective. Many programs like online certifications, virtual - laboratories etc are successfully making the learning experiences of millions of people easy and convenient [6].
Online Education has become the medium of knowledge for the people who do not have enough time to gain the knowledge at schools or colleges but still need to learn about the new trends. OE makes the process of learning more flexible. But along with this flexibility there arises the problem of interest and motivation to keep going with the learning process. A learner needs to be highly self-motivated and disciplined towards learning and should not get easily distracted [2].

\section{Advantages of Online Education}

There are several problems with the traditional system of education. First of all, a person needs to pay a huge sum of money just to attend a prestigious school. Secondly, it becomes very difficult to learn the actual concept because of the shortage of time span and inefficient structure of syllabus [10].

The foundation of Online Education is still stereotypical. People still think that the students going for the online education are not smart enough for a traditional school or the college or university, they are too lazy for maintaining the discipline of learning in the institute and the biggest of all is that they do not consider their degree as valuable as the one obtained through traditional institutes by attending physical classes. These believes of such people discourage many people interested in taking some online courses and force them to the traditional education making them spend a big deal of money, nerves and the years of their lives [5].

\section{Freedom to choose the course}

Although there is still a great freedom of choice for the learner to choose the course in the traditional education system but beside this advantage the drawback of this system is that the learner needs to shift to an unknown place or city and adapt himself to tough and challenging environment [7]. On the other hand Online Education overcomes this drawback and provides the same freedom of choice of course present in any traditional university to the learner. 


\section{Learn at ease}

Online Education overcomes the physical efforts which includes sitting in the classrooms for hours, travelling to faroff institutes etc [9]. The learner now needs a good internet connection and a computer to study from. All the study material and the required content like lectures and tutorials are provided over various online platforms.

\section{Self designed study schedule}

In case of the traditional education system all the students are taught according to the predefined approach and structure but not all the students can catch up to it and lag behind in learning. This is one of the biggest drawbacks of the traditional education system but on the other hand Online Education system lets the learner to decide the pace of learning that suits him the best and he can also schedule the strategy as well [9].

\section{Low price for equivalent knowledge}

It is a well known fact that the courses pursued through the Online Education system are way too cheaper than the same courses done through the traditional institutes [10]. In Online Education a learner only pays for what he is learning rather than paying for other resources like classrooms and electrical appliances. Some online portals also provide financial aid to the learners who can not afford the tuition fees for the courses [8].

\section{PROPOSED WORK}

The project that we have proposed focuses on establishing an interactive platform for students and teachers to enhance the performance of the students and finally getting better results. The students can always stay in touch with their teachers and fellow mates and discuss their problems. The teachers can respond to the queries asked by the students and can post different assignments and quizzes for the students to solve. The project aims to facilitate every member involved in the learning process with an online mechanism to stay connected to the community of other enthusiastic members.

The project is designed using tools namely Eclipse Oxygen.1a for web-designing and SQL Developer 17.3.1 for maintaining the database. Eclipse is the tool that provides the environment for developing the Java programs and is one the most widely used IDE (Integrated Development Environment) [4] whereas SQL Developer is the IDE for Oracle Database which support connectivity with many other databases as well [3]. The project consists of 3 different modules namely Admin, Faculty and the student with different functionalities as well as different responsibilities.

THE ADMIN has the actual control over the system and governs every activity that is happening in the system. The Admin can add a new faculty or a student and edit the details of any member and he has the authority to remove any member as well. Admin can also drop a message for the faculty members using a dedicated channel that can only be seen by the admin and the faculty.

THE FACULTY has the responsibility to update the attendance of every student and any kind of fine imposed on the student. Using this module one can upload the syllabus, assignment and the notes of the respective subjects. Teachers can also upload the marks of the tests in the students' records. Notices can also be circulated using the same portal. The content uploaded can be viewed by the students.

THE STUDENT has the minimum functionality as he can only view the content posted by the faculty members which includes the notes, the attendance, the imposed fine, the marks they got in the tests and any notice.

Apart from these modules another important part of the project is the database that it manages. We have used the ORACLE database in our project and all the data inserted by any of the user in the project is saved in this database.

\section{FUTURE SCOPE AND CONCLUSION}

With the proposed work one can easily learn about a particular subject with appropriate guidance and requisite study material.

There is still a large scope of development in the project.

- Query Discussion Forums - We can create a forum for the students and the faculties to discuss the queries raised by the students. The forum provides the opportunity to the students to sort their doubts and queries with the help of fellow students and the faculty members.

- Live Video Sessions - We can add this module to the system though which the registered users can attend the live video sessions by the teachers. In this way, students who are weak or are not able to attend the physical classes can take the advantage of this.

- Online Test Series - A module can be added for the mock tests and online tests series so that the students can know their performance level which can help them to prepare well in advance for the upcoming exams.

- Competitive Exam Oriented - This system can be made to focus on particular competitive exams. The syllabus and the study material for the subjects can be uploaded to the system which will be exam oriented

\section{REFRENCES}

[1] Ashwin Kumar, E-Learning, http://www.slideshare.net/AshwinKumar24/elearningppt

[2] Will Erstad, Online vs. Traditional Education: What You Need To Know, http://www.rasmussen.edu/studentlife/blogs/college-life/online-vs-traditional-educationanswer-never-expected/

[3] What is SQL Developer?, http://www.oracle.com/technetwork/developer-tools/sqldeveloper/what-is-sqldev-093866.html

[4] Wikipedia Contributors, Eclipse (software), http://en.wikipedia.org/wiki/Eclipse_(software)

[5] Chia-Wen Tsai, Research Papers in Online Learning Performance and Behaviour, Vol.17, Issue:1, Jan 2016, International Review of Research in Open and Distributed Learning

[6] Anna Sun, Xiufang Chen, Online Education and Its Effective Practice: A Research Review, Vol.15, 2016, Journal of 
Information Technology Education: Research, pp.157-190

[7] Tuan Nguyen, The Effectiveness of Online Learning: Beyond No Significant Difference and Future Horizons, Vol.11, Issue:2, June 2015, MERLOT Journal of Online Learning and Teaching

[8] Michael Hammond, A review of Recent Papers on Online Discussion in Teaching and Learning in Higher Education, https://secure.onlinelearningconsortium.org/sites/default/files /v9n3_hammond_1.pdf

[9] Stephanie Norman, 5 Advantages of Online Learning: Education Without Leaving Home,

https://elearningindustry.com/5-advantages-of-onlinelearning-education-without-leaving-home

[10] Thierry Volery, Deborah Lord, Critical success factors in online education, Vol. 14, Issue: 5, 2000, International Journal of Educational Management, , pp.216-223 